\title{
The Applications of APA Styles in African Academic Publications: An Evidence from Bahir Dar Journal of Education
}

\author{
Feyisa Mulisa \\ College of Education and Behavioral Science, Bahir Dar University
}

\begin{abstract}
Having skimmed through recently published articles of Bahir Journal of Education (BJE), I inadvertently engrossed with a few imperfections that are incompatible with a currently in use publication manual of the American Psychological Association (APA) style. Notwithstanding strong efforts have been made to produce high-quality articles in terms of contents, methodological approaches and scientific credibility, the oversights of very technical details of specific APA style and formatting have been found. From professional points of views, these oversights might certainly affect the quality of the journal. The main objective of this paper is to uncover the frequent errors that overlooked within the articles since 2014, and thereby to conquer the errors using sixth edition publication manual of the APA and up-to-date manuscripts that are available at the http://apastyle.apa.org/. I presented a series of errors observed in seven randomly selected articles regarding the titles, abstracts, citations, methods, statistical presentations and lists of reference entries to take viable measures that tackle the errors virtually. Finally, based on the observed mismatches, I forwarded implications for the quick use of publication manual of APA that could support the authors, the reviewers and the examiners of the journal articles.
\end{abstract}

Keywords: BJE; APA styles; publication manual; oversights; frequent errors

DOI: $10.7176 / \mathrm{IKM} / 9-2-01$

\section{Introduction}

In the last six months, I was skimming through some articles of BJE that have published since 2014 for reference purposes in other articles. Inadvertently, I engrossed with a few imperfections within the articles that are not compatible with the publication manual of APA style that is currently in use. Acknowledging all the endeavors made to suit the articles to the standards of APA, confronting several challenges such as shortage of resources supply that provide a piece of accurate and up-to-date information related to APA style, a few but important faults have been observed yet. BJE, as a peer-reviewed standardized journal of education, would publish highquality articles that could best meet all the basic criteria of up-to-date APA style. The frequent violation of the APA style within a given article can result in the rejection of the article even after the publication was issued (Onwuegbuzie, 2017). Therefore, in order to save the rejection of one or more of the BJE articles, it is worthwhile to uncover frequently committed errors that observed within the articles of BJE to enable the authors, the reviewer, and the editors conquer the unnoticed errors in instant accordingly.

$\mathrm{BJE}$ is a bi-annual journal of education that publishes articles from local and global studies related education policies, theoretical frameworks, and practices. Currently, by September 2017, BJE is working at its $17^{\text {th }}$ volume and second issues. Unlike many predatory journals those seek to accept as many articles as possible chasing for money from scholarly authors through publishing poor quality articles lacking best peer-reviewing practices (Beall, 2017), BJE performs a rigorous peer review processes and limits the scope of the articles to be published in a journal. Because peer review processes of paper are one of the means by which research can be prepared for final publication that increases its credibility (Patel, Pierce, Boughton, \& Baldeweg, 2017) BJE uses three blind reviewers to evaluate the quality and appropriateness of the given articles. Broadly speaking, the primary goal of BJE is to publish and disseminate highest quality research outputs that fit with international standard and values, (Bahir Dar Journal of Education, 2014) although measuring the quality of a given research article is a complex process (Molina, Alfaro, Rosa, \& Alfaro, 2017). Hence, it is very important to revisit how the journal much could suit the envisaged international standard and values from the accurate application of the publication manual of the APA style perspective.

For a sound journal, one of the worldwide accepted and used standards and values is the accurate use of publication manual of the APA style (Mårtensson, Fors, Wallin, Zander, \& Nilsson, 2016). Katerattanakul, Han, \& Hong (2003) further attested that the journal's style and formatting can provide a clear picture of the actual value of a journal and its articles. For educational and psychological researchers, the proper use of APA style, hence, encourages a clear disclosure of information incomplete manner and allows minor distractions (American Psychological Association, 2010) that increase the values and credibility of the articles. That is why from its very beginning in 1929, the publication manual of the APA has been gradually evolving over decades and dedicated to set out a sound and rigorous standards for scientific communications (American Psychological Association, 2010). To succeed these aims, the publication manual of APA style devoted largely to guide authors, reviewers and editors of a journal to prepare articles in clearly and concisely ways, to use common writing styles and 
layouts, display their findings, to credit sources of citations, and to write references in prescribed set of recipe (American Psychological Association, 2010; Hughes, Brannan, Cannon, Camden, \& Anthenien, 2017). Perhaps, the inability to strictly adhere to the rules and up-to-date guidelines of APA style may cause a failure to produce clear, standardized and valuable articles.

The proper use of publication manual of the APA in educational and psychological research is beyond providing comprehensive information and formats that often included in final reports of scientific endeavors (American Psychological Association, 2010; Wong et al., 2017). It enables the authors to avoid unintentional professional dishonesty and boosts up intellectual integrity (Skeen \& Zafonte, 2015). When preparing articles for publication it "is possible to use other people's words and ideas, but with mandatory labeling and reference to the source from which these words and ideas are taken" (Masic, 2013, p. 152) but it should be properly and completely done using APA style. A failure to acknowledge sources of citation properly cause plagiarisms, which can occur both intentionally and unintentionally, which less discouraged in developing countries (Balasubramanian, Bennett, \& Pierce, 2017; Kauffman \& Young, 2015). Particularly, academic plagiarism occurs extensively when the efforts to monitor a candidate reduced and opportunities to cheat increased (Etter, Cramer, \& Finn, 2006; Lipson \& Karthikeyan, 2016; Lucifora \& Tonello, 2015; Onwuegbuzie, 2017). Hence, the lenience to stick strongly to APA style among the journal reviewers and editors can definitely cause the high level of plagiarism and improper use of APA style.

The six edition of publication manual of the APA determined seven key potential areas of interest in scientific publications such as "ethics, journal article reporting standards, reducing bias in language, graphics, writing style, references, and statistics" to improve qualities of the scientific publications (American Psychological Association, 2010, p. xv). Despite this endeavor, pieces of evidence show that numerous authors often commit errors at least in one of the seven key distinguished areas by APA during submitting their articles for publication. But all these errors c considerably corrected with efforts of expert reviewers and editors before publication issued (Cash, 2009; Hughes et al., 2017; Kayla, 2015; Skeen \& Zafonte, 2015). Similar mistakes can be committing by the authors of BJE articles that could be corrected by the support of reviewers and editors before the final publication of the articles. But, what makes it different is that several standards of the APA style have been violated in BJE articles even after publications have issued that should have corrected with some efforts. In order to avoid the violation of these specific technical errors, informing the reviewers and the editors the potential areas of interests that seek further attention to applying the APA style accurately is very important (Author, 2007; Landrum, 2013; McDonald, 2011).

In fact, it is the very challenge for the majority of the authors, the reviews and the examiners to use the APA style accurately understanding the lengthily detailed rules (Alexander, 2006; Hughes et al., 2017; Kayla, 2015; Morse, 2009). One of these challenges for the authors, the reviewers and the editors to stick enduringly to the publication manual of the APA style is its frequent evolution and modifications (Mandernach, Zafonte, \& Taylor, 2016). Particularly in less developed countries such as Ethiopia, where limited bibliographical databases and the scarcity of up-to-date academic resources is a usual occasion, inability to become essentially perfect could not be a surprise. In such contexts authors, reviewers and editors of an article can unintentionally rely on their prior outdated experience that might be incompatible to the current standard. Regardless of what the context is, a standard article published in a peer-reviewed journal should contain high-quality design, clear methodological procedures and theoretical frameworks for its worthiness (Chacón-moscoso, Sanduvete-chaves, \& Immekus, 2017; Field, Booth, Ilott, \& Gerrish, 2014). Therefore, for BJE, once stuck to APA style as a basic standard that guides its authors, reviewers, and editors, the proper use the APA manual should not be compromised having a stand that scientific thinking develops with high efforts (Lilienfeld, 2010).

This paper, therefore, could provide better opportunity to discuss the up-to-date in use of APA styles than merely presenting the summary of errors observed in the journal articles for the stakeholders. The objectives of this article are, hence, to uncover the frequently committed errors within the articles and to provide useful sight into how the authors, the reviewers and the editors of the journal articles could become more efficient to conquer the overlooked errors. Additionally criticisms of less conscientious authors, reviewers and editors would appear indirectly as part of the critiques (Kennette \& Frank, 2013; Lucifora \& Tonello, 2015; Reynolds-Keefer, 2010). Finally, this study aimed at supporting the reviewers and the editors to recognize the parts of the journal that need more attention regarding the use of APA style. In order to guide the analysis of the papers, the following research questions were forwarded:

1. What are the frequently committed errors related to using publication manual of the APA style within BJE articles?

2. How the authors, the reviewers, and the editors could instantly conquer these frequently committing errors related to APA styles?

3. What measures could improve the overall quality of the articles with regard to APA styles? 


\section{Method}

In this short survey, mixed research designs were used. The quantitative research methods were used to manipulate counting errors and present them numerically whereas qualitative methods used to present observed errors thematically and word-by-word.

\section{Sample and sampling procedure}

The samples of this study were seven randomly selected articles that have published in BJE since 2014. Namely the selected articles were Bekalu Taye (2017); Dawit A. Getahun, Getachew Adamu, Awoke Andargie \& Jejaw D. Mebrat (2016); Demoz Degefe (2014); Fentahun Ayele \& Tsegaye Berhe (2014); Kibrom M. Feleke (2014); Leul T. Sidelil (2015), and Reda D. Negassi (2016) using lottery method to ideally include one article from each issue into this analysis. All these articles are available at http://www.bdu.edu.et/page/bahir-dar-journaleducation for free in addition to its printout copies at the library.

\section{Data collection methods}

Data were collected using manual and computer-assisted counting to explore APA style related oversights. The commonly observed errors that occurred within the articles were counted and recorded based on identified areas of interests. Further, based on the Batovski (2008) research paradigm, I used critical review approach and analytical textual method to transform a collection of technical figures into coherent texts to describe thematically.

\section{Coding procedures}

The APA style error search conducted in the seven randomly selected articles that yielded records that vary from the number of words in the title of the articles to the reference entries, and from qualities materials used in the articles to the recency of the quoted materials. The frequent errors that observed in the articles were grouped into seven categories based upon the potential areas of determination by American Psychological Association (2010): title, abstract, keywords, quotation, method, statistical presentation, and reference entries. I followed a coding protocol presented in figure one.

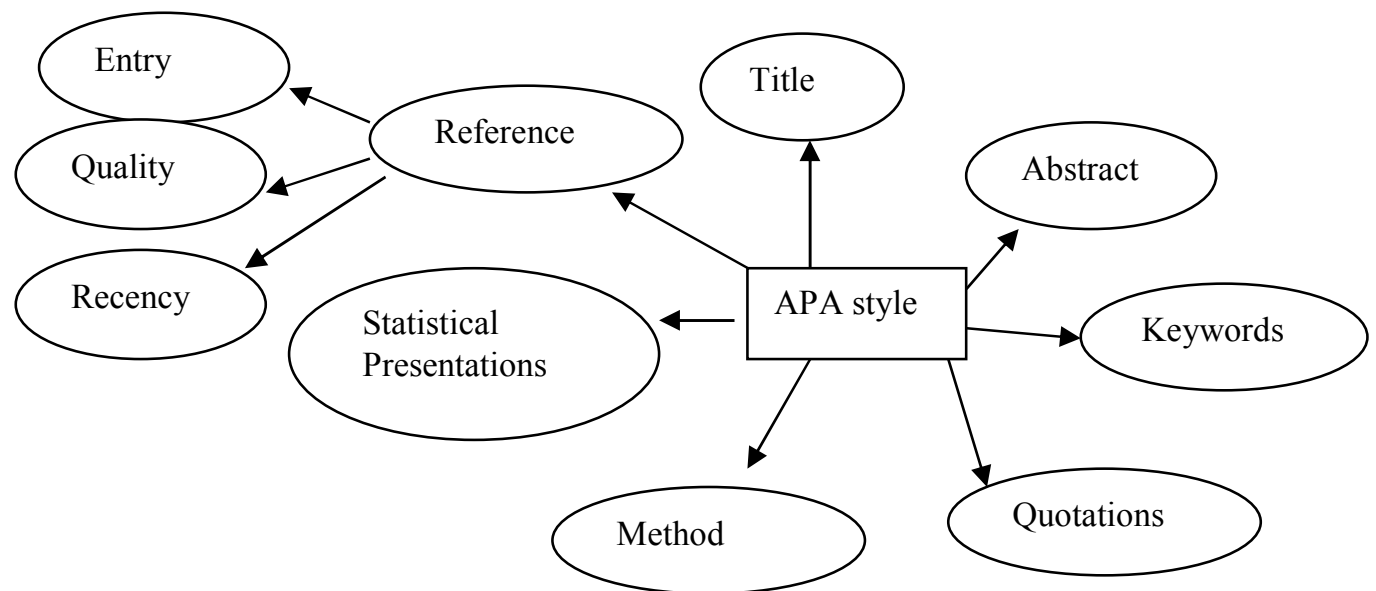

Fig. 1. The coding protocol procedure

\section{Results}

The standard educational journal requires an established set of rules and regulations that guide the scientific community of practice. In order to align BJE along with this assumption, strict adherence of the journal to APA style is one of the essential requirements as stated earlier. Based on the objective to conquer the APA errors that often committed in BJE, I presented the observed errors and suggest tips of feasible directions. Hereunder, my specified lists of incompatible entries related to APA style that may reduce the quality of the articles in particular and quality of the journal, in general, were addressed. Thus I pointed out the specific areas that need firm APA style consideration for the authors, for reviewers and the editors. 
Table 1

Common areas of oversights within the journal articles

\begin{tabular}{|c|c|c|c|c|}
\hline Article authors & $\begin{array}{l}\text { Publication } \\
\text { Year }\end{array}$ & $\begin{array}{l}\text { No words if a } \\
\text { title }\end{array}$ & $\begin{array}{l}\text { No of words in the } \\
\text { abstract }\end{array}$ & Method stated \\
\hline Bekalu A.Taye & 2017 & 10 & 144 & Methodology \\
\hline Dawit A. Getahun et al. & 2016 & 15 & 250 & Methodology \\
\hline Demoz Degefe & 2014 & 12 & 171 & Methodology \\
\hline Fentahun & $\&$ & & & Research \\
\hline Tsegaye Berhe & 2014 & 18 & 132 & methodology \\
\hline Kibrom M. Feleke & 2014 & 20 & 206 & Methodology \\
\hline Leul T. Sidelil & 2015 & 9 & 174 & No method \\
\hline Reda D. Negassi & 2016 & 13 & 381 & No method \\
\hline
\end{tabular}

Title of the articles

The publication manual of the APA style has an unequivocal standard for what the title of the articles should look like. The standing alone title of the article should concisely communicate the variables or theoretical issues under investigation in a limited number of words. For instance "the recommended length for a title is no more than 12 words" (American Psychological Association, 2010, p. 23). As a rule of a thumb, terms such as the study of, assessment of, investigation of, an experiment of and similar entries should not normally appear in a title whereas terms such as a research synthesis or a meta-analysis are an important clue for potential readers (American Psychological Association, 2010). Therefore, authors, reviewers and editors of the articles should limit words embedded in the title of the article to 12 or below and avoid the use of action verbs such as the study of, assessment of, investigation of, an experiment of and etc in the title of the articles.

\begin{abstract}
of the articles
The articles' abstract is a brief comprehensive summary of the contents that enable readers to assess the article quickly (American Psychological Association, 2010). It serves as a tool that provides a brief overview of the research to readers at a glimpse (Hughes et al., 2017). Because it is the most important part of the manuscript, an effective abstract is often characterized by not too much or too little in its wording. According to the six edition publication manual of the APA, the typical word limit of an abstract "should be ranging from 150 to 250 words" (American Psychological Association, 2010, p. 27). Having this as a standard, it was found that majority of the articles violated the publication manual of the APA style standard both in the lower and the upper limit boundaries. Some articles contained titles with less than 150 words, which is too little to be well informative whereas others contain more than 250 words, which might be loaded with trivial information. For example, the article of Fentahun Ayele \& Tsegaye Berhe (2014) contained an abstract as little as 132 words whereas the article of Reda D. Negassi (2015) contained an abstract as more as 305 words. As much as possible, to meet the standard of the APA journals, all the articles of BJE are required owning abstracts with 150 to 250 -word limits.
\end{abstract}

\title{
Keywords
}

In a given article, keywords are the three to five index terms that assist in creating database entries and online registration of the articles (Cash, 2009). Although the majority of the well-known world class standard journals across the world use their own unique standard of keyword entry styles, the six edition publication manual of the APA recommends using a semi-colon to separate one index terms from the others (American Psychological Association, 2010, p. 190). Despite this standard, all of the index terms within the BJE articles separated from one another with a comma. For sure, I have no stand to argue that BJE is using comma wrongly to separate index terms from each other and would change it into a semi-colon. Rather, I would like to merely indicate the preference of APA to separate index terms from one another is a semi-colon instead of using a comma.

\section{Quotation/Citation processes}

Although there is debate over whether a proper citation of the original sources increases the quality and credibility of an article at hand (Meyer, Waldkirch, Duscher, \& Just, 2017; Putnam \& Phelps, 2017), a poor citation can unarguably result in less acceptability of the article. With primary intention to improve the qualities of the BJE articles regarding citation processes, I scrutinized the selected manuscripts rapidly. The rapid scrutiny showed that there were few errors that could have been resolved easily. Let me begin with one of the frequently occurred subtle errors and progress to further errors that have the potential power to determine the journal's quality. For instance, among the subtle errors, a format how to write the author's name and page number in inthe test and block format was initially considered within the articles. In this article, when I was presenting the observed errors in the sample articles, once addressed it at a time in one or more of the articles and shown a direction how to conquer them, I ignored presenting the same type of errors in the other articles. So that, 
redundancy of the ideas and loading this paper with similar errors could be avoided. Accordingly, the authors, the reviewers, and the editors can firmly adhere themselves to APA style to solve the oversights that occurred in the previously published BJE articles.

With regard to the specific detail of citation styles, several minor and considerable errors have been recognized. For instance, in the article by Demoze Degefa (2014) only, I found numerous citation errors. In this article, beginning from the first page of the manuscript (page 17 of the journal), the format how page number was placed when citing the source was stylishly inappropriate. For example, I observed a citation style quoted as (Karren, 2009, p.31), which is against the APA style in one of the standards. According to the publication manual of APA style, the manuscript should be quoted in form of (Karren, 2009, p. 311), which needs space between page number (p) and the numerical figures (31). In the same article, the second bulky and junky citation error was the style used to express the locations of the page number in block quotations. The author used \#n to indicate the page number of the quoted manuscripts that observed seventeen times in the article. Additionally, I observed the third citation errors on page 24 of the article, which should be used in the in-text sentence format but had been cited in block format. The quoted material contained only 19 words so that it should be placed in the in-text sentence under the quotation mark. In the same manuscript, the same errors observed several times. According to APA, block quotation should only be applied if the cited materials are equal to 40 or more words (American Psychological Association, 2010, p. 170).

The second citation issue that attracted my attention was the use of et al. The use of an acronym et al., which refers to a principal author and other colleagues that prepared a quoted manuscript, has its own standard of entry. Indeed, if the given article was written by "three to five authors, writers should initially list the names of all authors, and subsequently use et al.; for six or more authors, et al. should be used immediately" (American Psychological Association, 2010, p. 177; Hughes et al., 2017, p. 158). Against the proper application of this standard, some authors of the BJE articles initially used et al. to indicate three or more authors ignoring to list the authors' last name for the first time. For example, in Bakalu A. Taye's article only, Horwitz, et al. (1991) on page 48, Brendgen, et al. (2007) on page 54, Chang, et al. (2004) on page 55 and Mejias, et al. (1991) on page 60 the use of et al. were appeared ignoring before initially listing the last name of authors. In the same article, despite the use of et al. should often follow with a comma such as (author, et al., year), all the et al., except in the entry of (Mejias et al., 1991) all others were followed by a period such as (Brendgen, et al. 2007), and (Horwitz, et al. 1991). In this regard, the authors, the reviewers and the editors of BJE articles are enthusiastically encouraged to use the et al. acronym properly in harmonious ways with APA style.

There is also another issue that has captured my attention in relation to citation processes but never categorized as an error in APA style. These are the cliché quote of one or few manuscripts in the given article that could reduce the value of the article at hand because the ideal articles are required to cite high-quality articles published in peer-reviewed journals properly (Masic, 2013). Particularly, the use of non-peer reviewed manuscripts such as reports, websites and overly relying on one or a few articles as a source of citation could reduce the value of the article under consideration. In fact, it is the responsibility of authors to search for all high-quality relevant publications, information, controversies and theoretical frameworks related to the article (Cash, 2009). Therefore, for the given weaknesses related to the quality of cited materials, authors would be either deserve acknowledged or criticized reasonably. In BJE articles, there were some weaknesses that need special considerations ahead. For instance, in Leul's (2015) article, the report of UNESCO, which was not published in a peer-reviewed manuscript and that APA calls gray literature, was cited 8 times. In the Reda D. Negassi's (2016) article, a book section known as Brown, Bransford, Ferrara, and Campione (1983) was cited 10 times. Unless the objective of the current article is a review, summary, or critique of the given article or manuscript, for example, American Psychological Association (2010) in case this article, relying exclusively on one or few manuscripts may awkward the progress of the article at hand. So that, overly citing one or few manuscripts to prepare an article should be discouraged by the reviewers and the editors.

In addition to cliché citation, using secondary citation - a citation of information from the secondary source, which is often thought of as tricky - frippery practice is more frequently occurring in some article. This form of citation could be applied sparingly only when the authors unable to obtain the original manuscript and not available in the English language (American Psychological Association, 2010; Hughes et al., 2017). In BJE articles, secondary citations deemed to be more common. For example, in Fantahun and Tsegaye's (2014) article, secondary citations occurred three times, in Reda D. Negassi's (2016) article, it occurred 15 times, whereas in Bekalu A. Taye's (2017) article it occurred five times. For better actions, the authors of the articles are strongly encouraged to use the originally published materials instead of relying on the secondary sources that might slightly alter the primary notions of the original manuscripts. Hence, the reviewers and the editors of the journal should place a strong value on the importance of citing primary sources that have been published in peerreviewed journals to evaluate a given article.

Regarding how to write the name of organizations as the author names, APA recommends all the authors to write the complete name of a given organization. For example, in the case of quoting APA materials in this 
article, applying $(A P A, 2010)$ is fairly inappropriate whereas the use of (American Psychological Association, 2010) correct. Against this standard, few violations were observed in BJE articles. For example, acronyms such as $O E C D$ and FDRE in Leul's (2015) article, BDU in Fantahun and Tsegaye (2014) and HESO in Kibrom's 2014 can be exemplary. In the case of no authors for a given manuscript quoted in an article, APA recommends to "move the title to the author position, and alphabetize the entry by the first significant word of the title" (American Psychological Association, 2010, p. 183). In contrast to this rule, the authors of BJE articles such as Bekalu (2017) used a dash symbol to show the absence of an author in the quoted manuscript.

Lastly, the concern related APA style that had captured the attention was the presentation of serial elements and concepts in the articles. Accordingly, in section 3.04, American Psychological Association, (2010) addressed three forms of seriations: (a) separate series of paragraphs, (b) separate series of sentences, and (c) separate series of elements. In this regard, the publication manual of the APA recommends series of paragraphs "such as itemized conclusions or steps in a procedure" (American Psychological Association, 2010, p. 63) could be identified by Arabic numerals. In the separate series of sentence case, unless the sentences have an ordinal connotation, they should not be presented using numerical values rather can be presented using bullets. In the separate series of elements case, the APA recommends using parenthesized letters instead of numbers. For example, ... this finding confirms that self-esteem can be boosted through (a) developing better self-concept, (b) reducing comparing oneself with others, and (c) active involvement in social interactions. Particularly, serial sentences and elements wrongly used by some authors such as Demoz Degefa (2014), Reda D. Negassi (2016) articles.

\section{The method section}

It seems that a little bit, there is confusion on the differences between the research method and research methodology. The description of the specific procedures that were used to conduct the given investigations refers to method whereas those introduce new methods into the scientific frontier, modifications of existing methods and discuss the analytic approaches of quantitative and qualitative to the scientific community refer to methodology (American Psychological Association, 2010; Willig, 2008). The method section of the article should be entitled precisely "Method" in a singular form and shouldn't be labeled methodology (American Psychological Association, 2010, p. 29; Hughes et al., 2017). In the majority of BJE articles, the method sections were entitled "Methodology", which were incompatible with the APA standard. Hence, it had better used the term "Method" instead of "Methodology" to surmount the application of APA style. In addition to using the terminologies, the methodological vagueness has been also observed in the articles. For example, methodologically, Leul's (2015 and Reda D. Neagassi's (2016) articles were much confusing. In these two articles, the method section was not stated for good and the articles were equivocal to label whether they were commentators, systematic reviews or qualitative studies. Hence, in every article that BJE publishes, the method section should be precisely stated to clearly communicate what the article is and how it was conducted to ensure the feasibility of the article's finding replication.

\section{Statistical presentations}

Unfortunately, among the selected sample articles, only one of them was conducted via quantitative research methods. Therefore, it could be committing a hasty generalization to make a conclusion about the qualities and appropriateness of statistical presentation in the articles based on a single article. In the stand-alone articleDawit A. Getahun et al. (2016)-the appropriate reporting of inferential statistics such as t, F, $\chi^{2}$, R etc were accurate. For the detail statistical applications in BJE articles, with a limitation that this article merely relied on seven randomly selected articles, among which only one article had significant statistical applications, I would prefer to recommend further analysis to address the issues related to statistical symbols and setups for better outputs.

\section{Reference section}

In scientific publications, reference entry is the information that enables readers in identifying and finding the original sources that were used within the article under consideration (Algozzine, Spooner, \& Karvonen, 2002; Masic, 2013). More than other parts of an article, it is in this section that most frequent mistakes occur (Borja, 2014). Despite this challenge, all the basic rules of reference entry must be consistently applied accurately and completely before a publication would be issued (American Psychological Association, 2010; Masic, 2013). This section once remained the very annoying problem that caused headaches among editors, can easily and preferably be prepared using common reference manager software such as Endnote, Mendeley, Zotero, Qiqqa, and colwiz. Specifically, Mendeley, Qiqqa, and Zotero are available for free online. So that the authors can download and use the software instantly whereas Endnote is available for subscription to avoid the majority of errors occur in the reference section entry.

In this article, the queries related to reference sections have examined from three perspectives: the entry of 
the reference per se, the quality of the quoted manuscripts as presented in Table 2, and the recency of the cited materials as presented as presented in Table 3. The entry of the references refers to whether all the reference materials mentioned in the reference section have been accurately written in scholarly acceptable APA standard. The quality of the references, on other hands, addresses how many materials mentioned in the reference entries were credible and reliable in terms of their contents-mainly published in peer-reviewed journals. The third, recency of the references, refers to how many recently published articles were included into the reference list because scientific evidence indicates that a typical article with the acceptable standard should cite approximately 20-30 high-quality articles published in peer-reviewed journals (Masic, 2013). On the other hand, a poorly prepared article could approximately 12 times to be rejected by reviewers and examiners and leads to a question about the author's conscientiousness (Cash, 2009; Onwuegbuzie, 2017).

When I begin with the lists of reference entries within the journal articles, missing corresponding references, poorly prepared writing styles and the use of digital object identifier (doi) were recognized as primarily important for quality articles. Majority of the articles contained at least one or more of the recognized weaknesses. Because APA has its own standard of reference entry, any practice against the standard might cause the high chance of rejection the article at hand. In BJE, although the majority of the articles reference sections written properly using the APA style, a few violations against the standard were observed. For example, let me pick out one of the complete reference entries observed in Kibrom M. Feleke's (2014) article labeled; 'Bahir Dar University (2006). Bahir Dar University Profile. Bahir Dar, Ethiopia'. How could the readers access this original manuscript? How do the reviewers could validate the credibility of the cited manuscript? In this sense, the authors should clearly reveal the manuscripts they used in the article and the location of the manuscripts. At the worst case, the APA style has been entirely ignored in the reference entry of Fentahun Ayele and Tsegaye Berhe's (2014) article. Most probably, it might be an IEEE style (the commonly used style in engineering sciences) of reference writing that are incompatible with educational journals.

In addition to applying for a complete reference entry appropriately, there is also another important issue to be considered-the massive inconsistencies of how to write a title of a book, a title journal, or title other materials in reference entry. Particularly, this focuses on when and how capitalization should be applied when writing the title of the manuscripts. Let me begin with a live example that might cause disagreement on how to write a title of a given manuscript in reference entry.

\section{Example A}

Beall, J. (2017). Predatory Journals, Peer Review, and Education Research. New Horizons in Adult Education \& Human Resource Development, 29(1), 54-58. https://doi.org/10.1002/nha3.20173

\section{Example B}

Beall, J. (2017). Predatory journals, peer review, and education research. New Horizons in Adult Education \& Human Resource Development, 29(1), 54-58. https://doi.org/10.1002/nha3.20173

In the example, A, capitalization of each first letter of the words in the sentence has done. In example B, except the first letter in the first word of the title, capitalization was avoided. Which of the two examples is the preference of APA? The answer is easy! The entry style in example A is no more preferable whereas the entry in example B is more recommended. Hence, all the reference entry in BJE articles shall be prepared always in the example B format except a word proceeded by a colon. In other words, it should not be written in form of:

Beall, J. (2017). Predatory Journals, Peer Review, and Education Research. New Horizons in Adult Education \& Human Resource Development, 29(1), 54-58. https://doi.org/10.1002/nha3.20173

Next, to the proper application of reference entries, the missing corresponding references were the second variable that I gave substantial emphasis. Indeed, it was also found that there are a few incompatibilities between the lists of the authors mentioned in the references sections and that they cited in the main body of the manuscripts and vice versa. For example, FSS (2008) in Demoz Degefa's article, Flick (2009) in Kibrom M. Feleke's article, and Abu-Rubia (2002) and Brendgen et al. (2007 in Bekalu A. Taye's article were among those mentioned in the main manuscripts and missed in the reference lists. Reversely, in Bakealu A. Taye's article only MacIntyre \& Gardner (1989), Brendger, M.; Bukowski, W.; Wanne, B.; Vitaro, F.; Tremblay, R. (2007) and Abu-Rabia (2002) were among the articles that mentioned in the lists reference entry but not cited in the main manuscripts. The observed mismatch appeared due to either the cited authors in the main manuscripts that were missed in the reference section; the erased citation remained in the reference list or wrongly spelled.

Another topic that was considered as an error in relation to the reference section entry was a format how to list the names of the editors of the given books. As a rule of a thumb, if a book section with an editor or editors had cited in an article, its correspondence reference entry should be written in form of In E. E. Editor (Ed.) format (American Psychological Association, 2010, p. 184). That means, for editors, unlike the typical authors' name of the books or articles, the initial names would appear before surnames of the editors (Hughes, et al., 2017). Currently, in BJE articles, it was found that some authors such as Bekalu A. Taye, Leul T. Sidelil, and 
Kibrom M. Feleke were duly violated this standard using an In Editor, E. E. (ed.) format. As a result, the authors, the reviewers and the editors of the journal articles would strongly insist on using the In E. E. Editor (Ed.) format, instead of using In Editor, E. E. (ed.) format.

One of the very overlooked errors, yet less considered by the authors, the reviewers, and the editors was the use of dash styles to separate page numbers of the cited manuscripts within the articles. APA identified three forms of symbols that structurally and physically resemble each other but used for different purposes. These symbols are known as "hyphens, dashes, and minus signs, which are each typed differently" (American Psychological Association, 2010, p. 97). Both hyphens and minus signs should not be used in reference entry to separate the page number of an article that quoted in the manuscripts. It would be a dash that serves to separate the page number of a given article or a book section. Even after attesting that it must a dash that properly separate page numbers of cited materials, APA, identified there are two types of dashes that an author should aware before to use them in a given article. These two types of dashes are called en dash and em dash. To separate the page numbers in a reference entry that have cited in the current materials, em dash $(-)$ is the proper symbol the authors should use without space before and after the dash. In all the sample articles the included in this work, except one article that used both hyphens and em dashes together, the authors exclusively relied on using use hyphen to separate page numbers of the articles and book sections. Therefore, to separate page numbers of the cited articles or book section, em dashes should be used by the entire authors of the BJE articles and the use of hyphen or en dash should not be tolerated by the reviewers and the editors.

APA recommends all authors to include doi address of the given article to the reference entry if it is already assigned and, in case, if there is no doi, the digital address URL (a uniform resource locator) of the article, newsletter, or magazine should be assigned (American Psychological Association, 2010, p. 198). Once launched in 1997 "to facilitate the long-term access and identification of objects in digital environments" (Boudry \& Chartron, 2017, p. 1453), this alpha-numerical code enables the readers to directly access the quoted materials online (Tocháček, 2015). Consequently, a doi of a given article should be included into the given reference entry following a prescribed format of dio entry such as dio: xx.xxxxxx, for example, doi: 10.1016/j.actpsy.2017.07.010 with no period at the end of doi (American Psychological Association, 2010, p. 190). Recently, in March 2017, there was an agreement to modify the format of doi entry. Hence, today dio of a given entry should be written in form of https://doi.org/xx.xxxxxx (APA Style, 2017). The typical example of writing dio today is https://doi.org/10.1002/nha3.20173. In all of BJE articles included in the sample when working on this article, except two entries in Demoz Degefa's article, doi was exclusively overlooked. Thus, I would like to strongly push all the authors, the reviewers, and the editors of the journal to integrate doi of the quoted manuscripts into the reference entry of the BJE articles.

Table 2

Qualities of the reference materials used in the sample articles

\begin{tabular}{|c|c|c|c|c|c|c|}
\hline Lists of authors & $\begin{array}{l}\text { Journal/proceeding } \\
\text { articles }\end{array}$ & $\begin{array}{l}\text { Books/ } \\
\text { section }\end{array}$ & Reports & Thesis/Dissertation & $\begin{array}{l}\text { Web } \\
\text { info }\end{array}$ & Unknown \\
\hline Bekalu A. Taye & 13 & 17 & 8 & 6 & 4 & - \\
\hline $\begin{array}{l}\text { Dawit A. } \\
\text { Getahun et al. }\end{array}$ & 30 & 9 & 3 & 1 & - & - \\
\hline $\begin{array}{l}\text { Demoz Degefe } \\
\text { Fentahun Ayele }\end{array}$ & 2 & 3 & 4 & - & - & - \\
\hline \& $\quad$ Tsegaye & & & & & & \\
\hline Berhe & - & - & 17 & - & - & 6 \\
\hline $\begin{array}{l}\text { Kibrom } \quad \text { M. } \\
\text { Feleke }\end{array}$ & 5 & 5 & 12 & 1 & - & 4 \\
\hline Leul. & 8 & 13 & 17 & - & - & 1 \\
\hline Reda D. Negassi & 19 & 26 & 5 & - & - & 1 \\
\hline Total & 77 & 73 & 66 & 8 & 4 & 12 \\
\hline
\end{tabular}

Scholars have a strong belief that the qualities of the manuscripts that have been cited within a given article can matter the quality of the current article per se (Nieminen, Carpenter, Rucker, \& Schumacher, 2006). That is why Masic (2013) argued a typical article with an acceptable standard of quality should cite at least 20 to 30 articles that were previously published in peer-reviewed journals. Accordingly, the qualities of cited manuscripts within the BJE articles were presented in Table 2. The table shows us the summary of the manuscripts type that the authors used to cite when they were preparing articles for BJE. According to this standard, among the sample articles, only one article best satisfies the minimum requirement to be accepted as a quality article published in a peer-reviewed journal. Particularly, the use of organizations' reports accounted for major source manuscript categories cited in the articles. Although, using reports, websites and other manuscripts that have not reviewed by experts can be cited sparingly to show the concern at hand, relying largely on these manuscripts might result in junk-in and junk-out processes. 
For example, against the argument of Masic (2013) who is arguing an article should cite at least 20 previously published articles in peer-reviewed journals, Demoz Degafa (2014) cited only nine manuscripts to complete the entire work of his article among which two of these manuscripts were articles published in peerreviewed journals. Similarly, in Leul T. Sidelil's (2015) article, only six articles that were published in a peerreviewed journal were cited whereas the article of Dawit, A. Getahun; Getachew Adamu; Awoke Andargie \& Jejaw D. Mebrat (2016) would be a model that cited 30 articles that have published in peer-reviewed journals. Therefore, I would like to push the authors, the reviewers and the editors to rely primarily on peer-reviewed publications and avoid the frequent quote of reports, websites, and unknown sources during preparing their articles.

Table 3

Recency of the references used in the sample the articles

\begin{tabular}{|c|c|c|c|c|c|c|c|c|}
\hline Lists of authors & $\leq 1990$ & $\begin{array}{l}1991- \\
1995\end{array}$ & $\begin{array}{l}1996- \\
2000\end{array}$ & $\begin{array}{l}2001- \\
2005\end{array}$ & $\begin{array}{l}2006- \\
2010\end{array}$ & $\begin{array}{l}2011- \\
2015\end{array}$ & $\begin{array}{l}2016 \\
\text { Later }\end{array}$ & $\mathcal{\&}$ \\
\hline Bekalu A. Taye & 6 & 6 & 9 & 14 & 12 & 1 & - & \\
\hline Demoz Degefe & - & - & 3 & 3 & 3 & - & $*$ & \\
\hline Dawit A. Getahun et al & 12 & 4 & 5 & 3 & 3 & - & - & \\
\hline Fentahun Ayele \& & & & & & & & & \\
\hline Tsegaye Berhe & 17 & - & - & - & - & - & $*$ & \\
\hline Kibrom M. Feleke & - & 1 & 1 & 13 & 12 & - & $*$ & \\
\hline Leul T. Sidelil & 1 & 3 & 3 & 15 & 15 & 1 & $*$ & \\
\hline Reda D. Negassi & 19 & 11 & 12 & 3 & 5 & 1 & - & \\
\hline Total & 55 & 25 & 33 & 51 & 50 & 3 & - & \\
\hline
\end{tabular}

*Represent an article that its scope of publication was before the given range of times

Not that the amount of manuscript mentioned in the qualities of the materials somewhat differs the number of manuscripts mentioned in the recency of the manuscripts because there were some manuscripts that had no clear date of publication.

Recency of the quoted materials in the given article is also one of the key indicators of the quality of the articles. Ideally, an article could cite manuscripts that have been published over decades to reveal the theoretical and practical backgrounds information of the issue under consideration. But there must be an emphasis on the recently published materials to show the urgency of the problem at hand (American Psychological Association, 2010; Mårtensson et al., 2016). The recency of manuscripts that had cited in the BJE articles has been presented in Table 3. The sample articles used in this work were published between 2014 and 2017. So that, the authors were expected cite few materials that published one or two decades ago and cite more manuscripts that published recently. In practice, it was found that the authors of the sample articles primarily cited the manuscripts that were published before 1990 and followed by those published between 2001 and 2005. Surprisingly, there were only three manuscripts included in the reference sections of BJE articles that published later than 2010. This shows that recently published articles, books, and proceedings were missed to address the current findings in the articles and the authors present the problem at hand from the decades older situations. There is no doubt that this limitation could matter the quality of the journal and needs further interventions. Therefore, I would like to finally recommend the authors to use few articles from manuscripts published years ago and rely largely on recently published peer-reviewed articles to prepare quality articles. Further, the reviewers and the editors would consider the importance of the recency of the cited materials to evaluate the given articles.

\section{Conclusion}

As per the primary motive of writing this article is a critique of the current oversights of APA styles in BJE and to suggest instant solutions accordingly, the observed errors were mentioned and suggestions were also forwarded. Mainly, in some cases, I preferred to delineate useful directions that supported by empirical examples to help the authors, the reviewers, and the editors prepare decent articles for the journal in good manners technically and stylistically. Therefore, BJE articles could become well prepared scientific manuscripts that could greatly impress its readers both in contents and styles. Of course, it should be noted that this article should not be viewed as a comprehensive guide to apply the APA style. Instead, it uncovers the oversights that occurred in the journal articles that increase conscious care for APA styles. In order to achieve the objectives of this article efficiently, updating oneself regularly with a frequently evolving APA styles is very important. Therefore, the authors, the reviewers and the editors of BJE articles should conscientious and have knowledge about the accurate use of each up-to-date technical detail of the publication manuals of APA style.

At this time it is unfortunate to observe the occurrences of considerable oversights APA style that have been found within the journal. In fact, it was the primary responsibility of the authors to prepare their papers accurately according to the APA style before submitting their articles to the journal; hence, they would receive professional criticisms accordingly. The reviewers and the editors also had a responsibility to check for the 
accuracy of APA style and could have turned the manuscripts back to the authors for further improvement before accepting them for publication to avoid the junk-in junk-out APA styles. Because a basic query why do these oversights have occurred was not the part of this article's objectives, there would be two hypothetical rationales: either a lack of up-to-date APA style knowledge or a poor professional ethical standard to remain honest to the scientific community. Whatever the reason is, in order to improve the quality of the journal ahead, there should be no room to tolerate any oversights of APA style as accurate as the journal fits the highest international standard.

To surmount the use of APA style in BJE articles, efforts must be made from three points of views. The first is facilitating situations on how to improve the up-to-date awareness of the authors, the reviewers and the editors of BJE articles. Mainly, the reviewers and editors should develop expertise in APA styles to guide and comment on the authors work. Second, acknowledging that it is very challenging to get all reviewers with APA style expertise, independent editors that evaluate the accurate use of APA style would be assigned before accepting the given articles for publication. Lastly, to enable the valid evaluation of the accuracy of APA style within a given article, clear, user-friendly, and specific rubric that measures the APA style would be prepared to guide the reviews and publication processes. Indeed, it would be possible to produce articles that best fit with the highest standard of the APA publication manuals.

\section{References}

Alexander, H. A. (2006). A view from somewhere: Explaining the paradigms of educational research. Journal of Philosophy of Education, 40(2), 205-221. https://doi.org/10.1111/j.1467-9752.2006.00502.x

Algozzine, B., Spooner, F., \& Karvonen, M. (2002). Preparing special education research articles in APA style. Remedial and Special Education, 23(1), 24-30. Retrieved from https://eric.ed.gov/?q=APA+manual\&pg=4\&id=EJ641051

American Psychological Association. (2010). Publication manual of the American Psychological Association. Washington, DC: Library of Congress Cataloging.

APA Style. (2017). APA Style Products. Retrieved September 9, 2017, from http://apastyle.apa.org/

Author. (2007). Who cares about APA policy and does it have an impact? 2006 annual report of the APA policy and planning board. The American Psychologist, 62(5), 491-503. https://doi.org/10.1037/0003066X.62.5.491

Bahir Dar Journal of Education. (2014). Bahir Dar journal of education home profile. Retrieved September 2, 2017, from https://bdrjournal.files.wordpress.com/2013/11/call-for-paper1.pdf

Balasubramanian, P., Bennett, V. M., \& Pierce, L. (2017). Journal of economic behavior \& organization the wages of dishonesty: The supply of cheating under high-powered incentives. Journal of Economic Behavior and Organization, 137, 428-444. https://doi.org/10.1016/j.jebo.2017.03.022

Batovski, D. A. (2008). How to write a review article. Retrieved September 20, 2017, from https://www.researchgate.net/profile/Dobri_Batovski/publication/235985751_How_to_write_a_review_art icle/links/0deec5163dd86347b9000000/How-to-write-a-review-article.pdf

Beall, J. (2017). Predatory journals, peer review, and education research. New Horizons in Adult Education \& Human Resource Development, 29(1), 54-58. https://doi.org/10.1002/nha3.20173

Borja, A. (2014). 11 Steps to structuring a science paper editors will take seriously. Retrieved September 21, 2017, from https:/www.elsevier.com/connect/11-steps-to-structuring-a-science-paper-editors-will-takeseriously

Boudry, C., \& Chartron, G. (2017). Availability of digital object identifiers in publications archived by PubMed. Scientometrics, 110(3), 1453-1469. https://doi.org/10.1007/s11192-016-2225-6

Cash, T. F. (2009). Caveats in the proficient preparation of an APA-style research manuscript for publication. Body Image, 6(1), 1-6. https://doi.org/10.1016/j.bodyim.2008.10.003

Chacón-moscoso, S., Sanduvete-chaves, S., \& Immekus, J. C. eds. (2017). Methodological quality of interventions in psychology. Lausanne: Frontiers Media. https://doi.org/10.3389/978-2-88945-249-1

Etter, S., Cramer, J. J., \& Finn, S. (2006). Origins of academic dishonesty: Ethical orientations and personality factors associated with attitudes about cheating with information technology. Journal of Research On Technology In Education, 39(2), 133-155. Retrieved from http://citeseerx.ist.psu.edu/viewdoc/download?doi=10.1.1.471.6371\&rep=rep1\&type=pdf

Field, B., Booth, A., Ilott, I., \& Gerrish, K. (2014). Using the Knowledge to Action Framework in practice: a citation analysis and systematic review. Implementation Science, 9(172), 1-14. https://doi.org/10.1186/s13012-014-0172-2

Hughes, J. L., Brannan, D., Cannon, B., Camden, A. A., \& Anthenien, A. M. (2017). Conquering APA style: Advice from APA style experts. Psi Chi Journal of Psychological Research, 22(3), 154-162. https://doi.org/10.24839/2325-7342.JN22.3.154

Katerattanakul, P., Han, B., \& Hong, S. (2003). Objective quality ranking of computing journals. 
Communications of the ACM, 46(10), 111-114. https://doi.org/10.1145/944217.944221

Kauffman, Y., \& Young, M. F. (2015). Digital plagiarism: An experimental study of the effect of instructional goals and copy-and-paste affordance. Computers and Education, 83, 44-56. https://doi.org/10.1016/j.compedu.2014.12.016

Kayla, D. (2015). Top five mistakes of APA style. Retrieved September 2, 2017, from http://ucwbling.chicagolandwritingcenters.org/top-five-mistakes-of-apa-style/

Kennette, L. N., \& Frank, N. M. (2013). The value of peer feedback opportunities for students in writing intensive classes. Psychology Teaching Review, 19(2), 106-111.

Landrum, R. E. (2013). Writing in APA style: Faculty perspectives of competence and importance. Psychology Learning and Teaching, 12(3), 259-265. https://doi.org/10.2304/plat.2013.12.3.259

Lilienfeld, S. O. (2010). Can psychology become a science? Personality and Individual Differences, 49(4), 281288. https://doi.org/10.1016/j.paid.2010.01.024

Lipson, S. M., \& Karthikeyan, L. (2016). The art of cheating in the 21 st millennium: Innovative mechanisms and insidious ploys in academic deceit. International Journal of Education, 8(2), 48-72. https://doi.org/10.5296/ije.v8i2.9117

Lucifora, C., \& Tonello, M. (2015). Cheating and social interactions: Evidence from a randomized experiment in a national evaluation program. Journal of Economic Behavior \& Organization, 115, 45-66. https://doi.org/10.1016/j.jebo.2014.12.006

Mandernach, B. J., Zafonte, M., \& Taylor, C. (2016). Instructional strategies to improve college students ' APA style writing. International Journal of Teaching and Learning in Higher Education, 27(3), 407-412. Retrieved from http://www.isetl.org/ijtlhe/

Mårtensson, P., Fors, U., Wallin, S., Zander, U., \& Nilsson, G. H. (2016). Evaluating research: A multidisciplinary approach to assessing research practice and quality. Research Policy, 45(3), 593-603. https://doi.org/10.1016/j.respol.2015.11.009

Masic, I. (2013). The importance of proper citation of references in biomedical articles. Acta Informatica Medica, 21(3), 148-155. https://doi.org/10.5455/aim.2013.21.148-155

McDonald, K. E. (2011). Teaching the 6th edition of APA style of writing in counselor education. Journal of Counselor Preparation and Supervision, 3, 124-145. Retrieved from http://repository.wcsu.edu/ cgi/viewcontent.cgi? article $=1031 \&$ context $=$ jcps

Meyer, M., Waldkirch, R. W., Duscher, I., \& Just, A. (2017). Drivers of citations: An analysis of publications in "top" accounting journals. Critical Perspectives on Accounting. https://doi.org/10.1016/j.cpa.2017.07.001

Molina, G. M., Alfaro, H. P., Rosa, S., \& Alfaro, P. (2017). Design and validation of a rubric to assess the use of the American Psychological Association style in scientific articles. Journal of New Approaches in Educational Research, 6(1), 78-86. https://doi.org/10.7821/naer.2017.1.220

Morse, G. G. (2009). Faculty application of the American Psychological Association style. The Journal of Nursing Education, 48(10), 48-60. https://doi.org/10.3928/01484834-20090610-10

Nieminen, P., Carpenter, J., Rucker, G., \& Schumacher, M. (2006). The relationship between quality of research and citation frequency. BMC Medical Research Methodology, 6(1), 42-49. https://doi.org/10.1186/14712288-6-42

Onwuegbuzie, A. J. (2017). Most common formal grammatical errors committed by authors. Journal of Educational Issues, 3(1), 109-140. https://doi.org/10.5296/jei.v3i1.10839

Patel, J., Pierce, M., Boughton, S. L., \& Baldeweg, S. E. (2017). Do peer review models affect clinicians' trust in journals? A survey of junior doctors. Research Integrity and Peer Review, 2(11), 1-8. https://doi.org/10.1186/s41073-017-0029-8

Putnam, A. L., \& Phelps, R. J. (2017). The citation effect: In-text citations moderately increase belief in trivia claims. Acta Psychologica, 179, 114-123. https://doi.org/10.1016/j.actpsy.2017.07.010

Reynolds-Keefer, L. (2010). Improving the quality of experience journals: Training Educational Psychology students in basic qualitative methodology. Teaching Educational Psychology, 6(1), 20-32. Retrieved from http://files.eric.ed.gov/fulltext/EJ894804.pdf

Skeen, T., \& Zafonte, M. (2015). Teaching APA style documentation: Discovery learning, scaffolding, and procedural knowledge. Journal of Instructional Research, 4, 69-75. Retrieved from http://files.eric.ed.gov/fulltext/EJ1127744.pdf

Tocháček, D. (2015). Use of digital learning objects across borders: Research on travel well criteria. Procedia Social and Behavioral Sciences, 171(Supplement $\quad$ C), $1209-1213$. https://doi.org/https://doi.org/10.1016/j.sbspro.2015.01.233

Willig, C. (2008). Qualitative Research (2nd ed.). New York: McGraw-Hill.

Wong, V. S. S., Iii, R. E. S., Aragón-garcía, R., Moon, Y. P., Ford, B., Haut, S. R., ... Elkind, M. S. V. (2017). Mentored peer review of standardized manuscripts as a teaching tool for residents: A pilot randomized controlled multi-center study. Research Integrity and Peer Review, 2(6), 1-9. 
https://doi.org/10.1186/s41073-017-0032-0

\section{Appendices}

The following articles were presented here below to demonstrate those selected and included in the sample from BJE articles that have been published since 2014 to work on this article.

Atnafu, B. (2017). Verbal Behaviors of Teachers and Student Anxiety in Language Classes. Bahir Dar Journal of Education, 17(1), 48-65.

Ayele, F., Management, H., Berhe, T., \& Studies, B. (2014). The Politics of Institutionalization, Professionalization and Quality Maintenance: Revisiting the Formative Years of the Academy of Pedagogy,. Bahir Dar Journal of Education, 14(1), 31-43.

Darge, R. (2016). Strengthening a Learning-Centered College / University Classroom in Ethiopia : Current Wisdom in Teacher Professional Development. Bahir Dar Journal of Education, 16(2), 82-107.

Degefa, D. (2014). Understanding Academic Freedom in Addis Ababa University: The Views of the Academics. Bahir Dar Journal of Education, 14(1), 17-30.

Feleke, K. M. (2014). The Institutional Impacts of Financial Inadequacy and Financial Inefficiency of Public Universities in Ethiopia : The Case of Bahir Dar. Bahir Dar Journal of Education, 14(1), 44-63.

Getahun, D. A., Adamu, G., Andargie, A., \& Mebrat, J. D. (2016). Predicting mathematics performance from anxiety, enjoyment, value, and self-efficacy beliefs towards mathematics among engineering majors. Bahir Dar Journal of Education, 16(1), 16-33.

Sidelil, L. T. (2015). The Ethiopian Higher Education Equity Policy and its Flaws. Bahir Dar Journal of Education, 15(2), 58-76. 